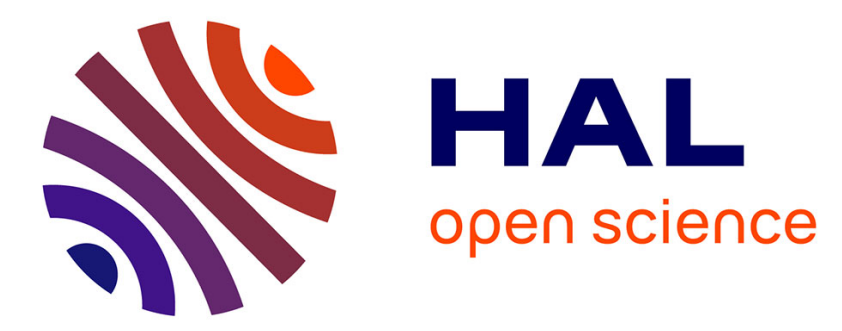

\title{
Simulating impacts of regulatory policies on urban freight: application to the catering setting
}

Sarra Jlassi, Simon Tamayo, Arthur Gaudron, Arnaud de La Fortelle

\section{To cite this version:}

Sarra Jlassi, Simon Tamayo, Arthur Gaudron, Arnaud de La Fortelle. Simulating impacts of regulatory policies on urban freight: application to the catering setting. 6th International Conference on Advanced Logistics and Transport, IEEE, Jul 2017, Bali, Indonesia. 10.1109/ICAdLT.2017.8547005 . hal-01571510

\section{HAL Id: hal-01571510 https://hal.science/hal-01571510}

Submitted on 2 Aug 2017

HAL is a multi-disciplinary open access archive for the deposit and dissemination of scientific research documents, whether they are published or not. The documents may come from teaching and research institutions in France or abroad, or from public or private research centers.
L'archive ouverte pluridisciplinaire HAL, est destinée au dépôt et à la diffusion de documents scientifiques de niveau recherche, publiés ou non, émanant des établissements d'enseignement et de recherche français ou étrangers, des laboratoires publics ou privés. 


\title{
Simulating impacts of regulatory policies on urban freight: application to the catering setting
}

\author{
Sarra JLASSI, Simon TAMAYO, Arthur GAUDRON, Arnaud de LA FORTELLE \\ CAOR - Centre de Robotique \\ MINES ParisTech, PSL Research University \\ 60 Bd. St Michel 75006 Paris, France \\ sarra.jlassi@mines-paristech.fr
}

\begin{abstract}
Regulatory policies aim at reducing the negative effects of urban freight transportation, especially those related to traffic, emissions and noise. Nonetheless, stakeholders in city logistics often have divergent objectives, which lead to difficulties upon defining the best possible choices regarding regulation. This paper presents a multi-agent and discrete-event based simulation of urban deliveries that aims at evaluating the impacts of regulatory policies. Restrictions regarding vehicle weights and time windows are considered in order to measure the impacts on deliveries based on total distances, number of vehicles, loading rates and air pollutant emissions. The simulation framework is applied to the delivery services for restaurants, in which 4 scenarios of regulation are evaluated in the city of Paris. One originality of the proposed approach is to use real data for the instantiation of agents and the GIS in the simulation.
\end{abstract}

Keywords - urban logistics, simulation, regulation, time access restrictions, vehicle weight restrictions.

\section{INTRODUCTION}

Nowadays urban freight draws a lot of attention due to its costs and environmental impacts. The situation leads to the willingness for the governments, communities, industrial companies and businesses to take action towards a more efficient city logistics. In Europe, freight transit and urban freight transport account for $31 \%$ of the energy use and $31 \%$ of the $\mathrm{CO} 2$ emissions in urban areas [1]. Although delivery vehicles represent only $10 \%$ of the traffic in urban zones (expressed in vehicles-kilometres), they are responsible for $20 \%$ to $60 \%$ of the air pollution and noise created by such traffic [2].

In order to improve quality of life in urban areas, cities implement various regulations regarding vehicles (size, weight, load factor and/or engine type) and restrictions of access (restricted areas and/or time windows). Public authorities mostly focus the regulations on trucks as they are considered to be the main cause of slowdowns and traffic congestion particularly during peak hours [3].

Numerous initiatives have been carried-out (Bangkok [4], Seoul [3], [5] , NY [6]) in order to shift movements of trucks from peak hours to off-peak hours. The foremost expected impacts relate to congestion, travel time, safety and pollution. NY off-peak deliveries are considered to have saved between $\$ 100$ and $\$ 200$ million/year in terms of travel times and pollution reductions [6]. Moreover, other road users perceived an improvement in their quality of life. Pedestrians and cyclist felt safer in the city. Additionally, the project estimated travel time savings of 3 to 5 min per trip for the non-freight travellers and about 48 minutes in travel time per delivery tour and 1 to 3 hours in total service time per delivery tour for freight carriers.

However, industrials, researchers and trade associations have claimed that these type of restrictions can be economically and/or environmentally detrimental (Castro and Kuse [3], NEDA [7], Quak and Koster [8]). On the one hand, the extra costs generated by the regulation would be paid by urban freight actors (shippers, carriers, etc.), resulting in operational changes and elevated overheads. On the other hand, the difficulty to keep the same level of service while complying with regulations would lead to logistic systems with higher environmental impacts [7]. This conjuncture points out the complexity of city logistics as each stakeholder has a different perspective and regulations have direct and indirect impacts that imply costs and benefits unevenly. As a result, it is particularly difficult to formalize and measure the impacts of regulation actions implemented by public authorities.

A holistic approach to regulation in city logistics seems mandatory. Although the multiplicity of actors and the heterogeneity of information related to urban freight, a formal description of the relations within such system would be hardly obtained. However, simulation appears to be a pertinent approach to study such relations, while avoiding the issue of formally describing the interactions between actors.

After exploring the literature referring to simulation in urban logistics, it was observed that a limited number of publications used real datasets on simulations. To date, there are few simulation works that study the impacts of public regulations in urban logistics [9].

This paper presents a simulation framework of urban deliveries that aims at evaluating the relations between regulatory policies and performance indicators. Restrictions regarding vehicle weights and time windows access are considered in order to simulate deliveries of goods in urban areas. The impacts of each regulation are measured in terms of total distances, emissions, lead-times, fleet sizes and loading rates.

\section{PROBlem STATEMENT}

The proposed simulation model aims at evaluating the relations between regulatory policies (vehicle weights and time 
windows) and performance indicators relevant to professionals and public authorities. Figure 1 presents the different urban entities considered in the proposed approach, as well as their main relationships and interactions. Each of these entities has its own behaviour and it influences the unwinding loop.

In the system, a group of businesses located in an urban area order products from a distributor. The distributor groups the orders, prepares them and then delivers the products with the help of a carrier that performs the deliveries in tours. These tours generate traffic and emissions as they involve a certain number of vehicles on the roads. The residents of the area perceive the effects of these deliveries and the public authorities establish regulations that constrain the organisation of the tours.

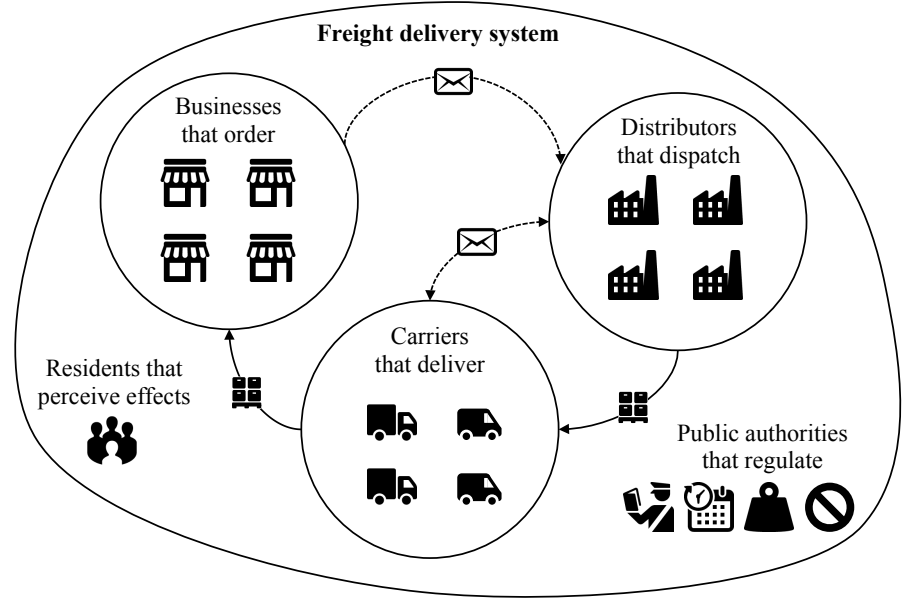

Fig. 1. Freight delivery system for the proposed simulation

This paper will focus on the two regulatory policies described in [10]:

- Vehicle size restrictions: which consist in banning the circulation in the city of certain types of vehicles based on their size, weight and/or loading factor.

- Time window restrictions: which consist in allowing freight vehicles to travel inside the restricted zones only during specific time windows. For instance, offpeak delivery regulations [6] intend to shift deliveries to the off-peak period.

This paper focuses on the city of Paris, which has undertaken important steps in order to become a "low-emission zone". Since 1991, the city approved acts to reduce the number of trucks entering the city [3]. In November 2014, a plan to combat air pollution was been launched. In September 2015, a decree introducing traffic restrictions for freight vehicles carrying more than 3.5 tonnes was issued. In January 2017, Paris became the first area in France to restrict the access to polluting vehicles by using a sticker-based regulation.

Although these measures are driven by the ambition of reducing the environmental impacts of urban freight, the studies of Manila [7], New York [6], and The Netherlands [8] revealed that they also yield important influences on the economic actors of the logistic setting. As a result, this research addresses three major questions:
- How can "Vehicle Size" and "Time Period" restrictions be related to measures of emissions, distances and lead times in a particular setting?

- What is the pertinence of replacing "heavy goods vehicles" by "light duty vehicles" in order to reduce emissions?

- What is the pertinence of changing the delivery timewindows in order to reduce the number of vehicles in an urban zone?

\section{SimUlation MODEL}

Simulation allows understanding how systems behave over time when different parameters and configurations are applied. In the proposed system (cf. figure 1), a simulation can evaluate scenarios in which "what if" questions are considered in order to better understand the behaviour of the system over time.

\section{A. Agent-based and discrete event logic}

This paper proposes agent-based and discrete-event simulation model. This choice was based on a thorough literature review on the different simulation approaches applied to urban logistics [9].

On the one hand, discrete-event simulation (DES) is known to be useful for problems that consist of queuing networks [11] and is capable of representing complex stochastic systems [12]. On the other hand, agent-based simulation (ABS) allows the representation of different stakeholders (shipper, transport service provider, carrier and driver) to act as independent decision-makers or behave as single entities [13], [14], and [15].

For the purpose of this paper, the idea of using a hybrid simulation model is appealing as it allows combining the advantages of both DES and ABS. The presented simulation model was developed using the Anylogic simulation software, a java-based multi-logic commercial simulation platform that has already proven its capabilities to model and simulate complex systems [16].

\section{B. Structure of the model}

The proposed simulation model includes different agents (i.e. businesses, distributors, vehicles, etc.) that interact with each other in the same urban zone.

The entry point of the simulation is related to the demand generation, in which businesses generate orders following a given probability distribution. Each order contains information about the distributor (address) and the requested merchandise (type, amount, etc.). If there is more than one distributor, orders are allocated to the closest.

During daytime, businesses place orders to the distributors. The model considers only next day deliveries with a cut-off hour of the distributor set at midnight. Therefore every night, the distributor will optimize the vehicles' tours and the loading layout based on the constraints of each scenario. The carriers will load the vehicles depending on the assignments of the distributor. Finally, the vehicles will perform their deliveries in the city. 


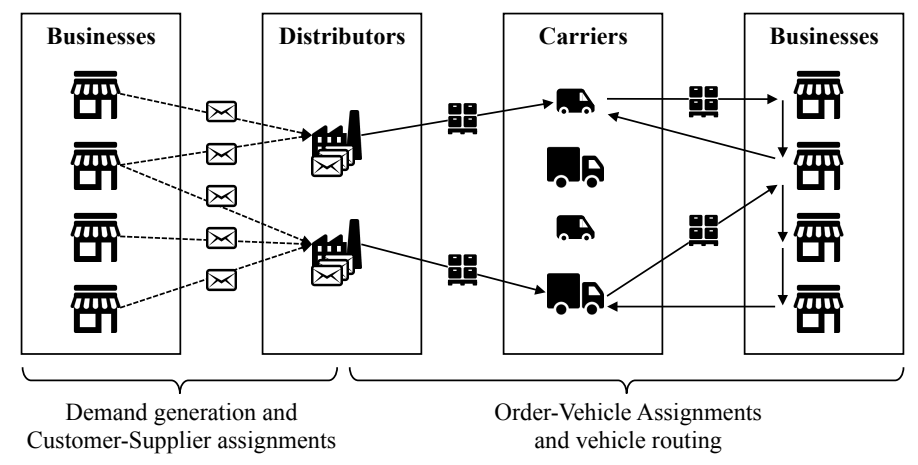

Fig. 2. Structure of the simulation model

Two types of vehicles are considered in this work: light duty vehicles commonly called vans, and heavy goods vehicles commonly called trucks. Table 1 shows the properties of each type of vehicle:

TABLE I. MAIN FEATURES OF THE SIMULATED VEHICLES

\begin{tabular}{|l|l|l|}
\hline Vehicle type & Van & Truck \\
\hline Capacity (ton) & 1.2 & 8 \\
\hline Speed urban area $(\mathrm{km} /$ hour$)$ & 25 & 25 \\
\hline Costs urban area $(€ / \mathrm{km})$ & 1.35 & 2.03 \\
\hline $\mathrm{CO}_{2}(\mathrm{~g} / \mathrm{km})$ & 299.5 & 943 \\
\hline $\mathrm{SO}_{2}(\mathrm{mg} / \mathrm{km})$ & 2.3 & 7.2 \\
\hline $\mathrm{NOx}(\mathrm{g} / \mathrm{km})$ & 0.55 & 3.1 \\
\hline
\end{tabular}

These values are obtained from the work of Van Heeswijk et al. [17] and Boer et al. [18], which consider circulation in urban areas for 2020 engine standards. It is to note that the emission factors considered in Table I, are consistent with those given by the HBEFA (Handbook Emission Factors for Road Transport, http://www.hbefa.net/Tools/).

\section{Stakeholders and performance indicators}

A large number of stakeholders are associated with urban freight transport. The simulation proposed here, intends to evaluate the requirements of 4 stakeholders, namely: freight carriers; residents; distributors and local authorities.

The simulation considers the following objectives for each stakeholder:

- Freight carriers aim at increasing transport profits while ensuring good customer service levels: this is done by reducing the operating costs of vehicles, that are proportional to the travelled times and distances.

- Distributors aim at selling their goods to customers while offering good service levels, particularly in terms of lead-time.

- Residents aim at improving quality of life by reducing emissions of $\left(\mathrm{CO}_{2}, \mathrm{NO}_{\mathrm{x}}, \mathrm{SO}_{2}\right)$. At the same time, they want restaurants and stores selling products at reasonable prices in their urban areas.
- Local authorities are responsible of health and safety of the residents. They aim at reducing emissions and traffic. At the same time, they are accountable for the economic dynamism of cities. As a result, they aim at implementing regulations that can reduce negative impacts, while avoiding elevated operating costs that would lead to higher cost of living.

Six performance indicators have been chosen to evaluate the objectives these stakeholders:

\section{Driven kilometres per tons of goods}

2. Loading rate of the vehicles entering the city (\%)

3. Average delivery time (hr)

4. Emission of $\mathrm{NO}_{\mathrm{X}}$ (g of $\mathrm{NO}_{\mathrm{X}} / \mathrm{kg}$ of goods)

5. Emission of $\mathrm{CO}_{2}\left(\mathrm{~kg}\right.$ of $\mathrm{CO}_{2} / \mathrm{kg}$ of goods)

6. Emission of $\mathrm{SO}_{2}$ (mg of $\mathrm{SO}_{2} / \mathrm{kg}$ of goods)

It is to note that in this work, special attention is paid to the emissions. Indeed, during the last decade peaks of pollution invade the city of Paris and even all the Ile-de-France region.

\section{Hypotheses}

In this application three main hypotheses are considered:

1) The service level is assumed to remain constant regardless of the scenario. That is to say, even if a certain regulation is applied, the distributor will adapt its capacity in order to guarantee the same quality level to the final customers. This means that the number of total delivered orders should remain constant and these orders should all respect the nextday delivery lead-time.

2) The fleet size is considered to be variable and it will adapt to the demand. As a result, the distributor will use more vehicles in order to fulfil the customer orders on time. This hypothesis is close to reality, as real fleets are dimensioned with previous knowledge of the consumption, and they can fluctuate on the grounds of subcontracting.

3) Two types of vehicles are considered, and the fleet is considered as homogenous (i.e. only one type of vehicle is composing the entire fleet). The fleet in the model is an average representation of a fleet in reality.

\section{E. Methodology}

Data collection is the first step to build the model. Indeed, in order to improve efficiency and provide long term plans it is crucial to have relevant data on what is being moved (type of goods), where (origins and destinations), when (time windows and frequencies) and by what means (transportation modes). A challenge in the freight distribution setting is that competitiveness is intense, and thus, information sharing is often perceived as a potential threat. This induces an important handicap when collecting data. In the proposed framework, the model is built upon a geographic information system (GIS) based on OpenStreetMap, which contains the roads and the addresses of entities. 
The second step is the parametric modelling, which consists in defining the appropriate probability distributions of the entities in model. That is, the parameters defining the probabilities for: 1) demand generation (in terms of frequency and quantity); 2) supply-demand assignments and 3) vehicle routing.

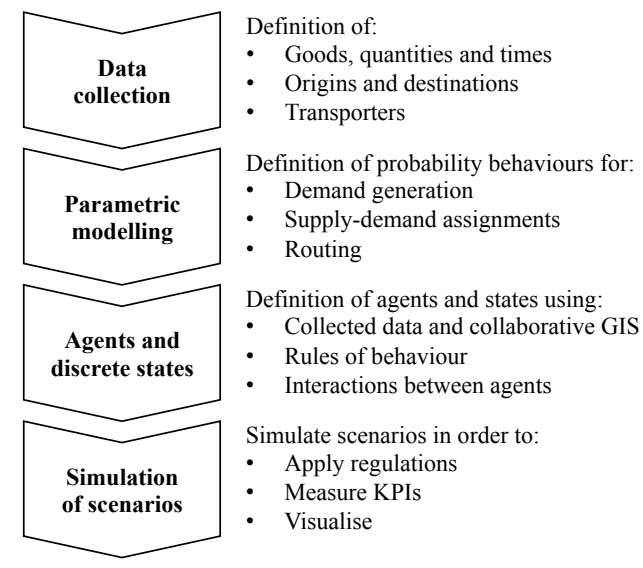

Fig. 3. Methodology of the proposed approach

The third step consists in creating the agents and the discrete event logic. In this step are defined the states and transitions for every agent as well as the overall communication rules that define the interactions between them.

The last step is simulation based scenario analysis. This step is used to analyse the impacts of a given evolution in one or more parameters of the system. In the presented case, this consists on evaluating and measuring the impacts of regulatory policies on deliveries based on total distances and emissions.

\section{APPLICATION TO THE CATERING SETTING IN PARIS}

This section illustrates the proposed framework by considering the deliveries from the Rungis market to a set of Restaurants in the city of Paris. The Rungis International Market is the world's biggest and leading fresh products market. It is located in the southern suburbs of Paris (48.761890, 2.361019), $11 \mathrm{~km}$ from the border of the city and $18 \mathrm{~km}$ from the centre of the city. Its clients are professionals, distributors and restaurants. The Rungis market starts its operation each day at 1:00 am and ends around 11:00 am. In the presented application, only restaurants will be considered.

The client's locations used in this simulation were provided by a geo-referenced customer's database. The total number of clients (restaurants) is 100 , that is 0.95 clients per square kilometre. Each restaurant issues an average of 6.5 replenishment orders per week ([19], [20]). These orders follow a uniform discrete distribution.

The delivery corresponding to every order is expected the next day $(\mathrm{AxB})$. A distributor in the Rungis market, processes the orders, performs the picking operation and then appoints a carrier to deliver the goods.

In our simulation, the orders are sent from the "business" agents (restaurants) to the "distributor" agent in Rungis. At the end of each day, the distributor agent performs an optimization of its deliveries in order to schedule the next day's tours. The optimization problem takes into account the loads of the current orders, the capacities of the available vehicles and the allowed time windows for delivery. The optimization aims at minimising the total distance and it is solved using Jsprit, a java-based open source toolkit for vehicle routing. The next day, the "vehicle" agents deliver the goods to the clients by taking the best-adapted roads to their itineraries using a GIS based on OpenStreetMap. The drop-off time follows a uniform distribution between 10 and 20 minutes per delivery. After finishing its tour each vehicle comes back to Rungis market. Additional delivery tours are done if time allows it.

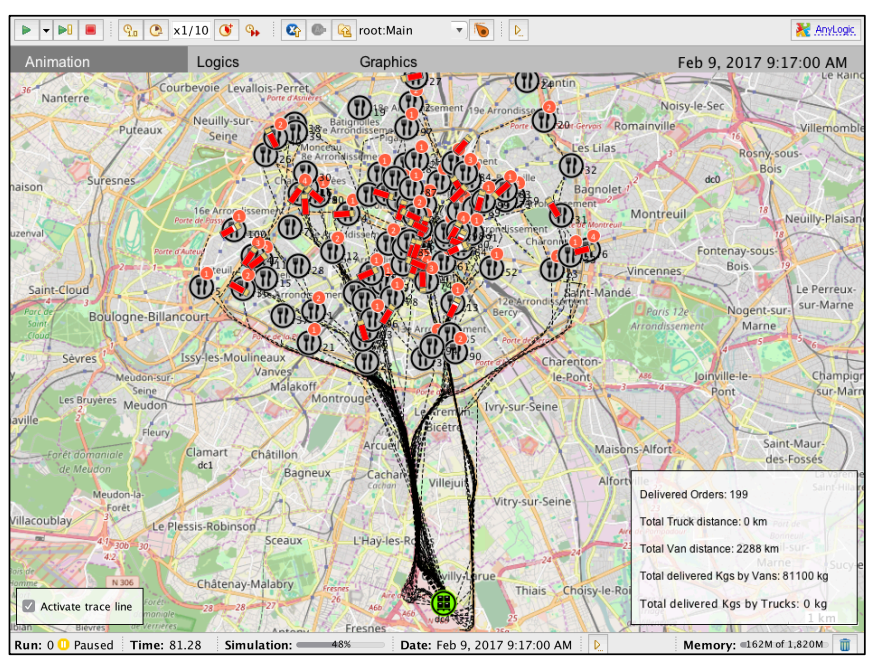

Fig. 4. APPLICATION TO THE CATERING SETTING IN PARIS

Figure 4 presents a snapshot of the simulation in which the agents "distributor", "business" and "vehicle" can be distinguished". Four scenarios of simulation are hereafter analysed.

\section{A. Scenario 0-Heavy trucks are authorized in an unconstrained time window}

The scenario 0 is used as a reference to study the impacts of the different regulations. In this first experiment, weight restrictions are not considered. Only trucks perform the deliveries. The public authorities do not regulate the timewindow of access. Nevertheless, deliveries must respect the timeslots indicated by the customers. As a matter of fact, in the catering setting, deliveries are completed from 8:00 am to 12:00 am.

\section{B. Scenario 1-Only light duty vehicles are authorized in an unconstrained time window}

This scenario simulates a weight restriction preventing trucks from entering the city. As a result, the trucks are replaced by vans. The time window for delivery remains identical (i.e. deliveries are done from 8:00 am to 12:00 am). Since the vans have a lower payload (1.2 ton against 8 ton), more vehicles will be needed in order to fulfil the customer orders in the same time window. 


\section{Scenario $2-$ Heavy trucks are authorized but the time window is constrained by the public authority}

In this scenario, time windows are constrained by the public authority. The deliveries are only allowed between 9:00 am to 11:30 am. Only trucks perform the deliveries.

\section{Scenario 3 - Only light vehicles authorized and the time window is constrained}

This last scenario combines both regulations: weight restriction and time windows restriction. As a result, vans perform the deliveries, and they are allowed in the city between 9:00 am to 11:30 am.

\section{F. Results}

In this practical application 4 experiments were run. Each simulation scenario corresponds to the deliveries of a week of virtual time. It is important to recall that the service level is assumed to remain constant regardless of the scenario. This means that for each case the total delivered amount of goods is equivalent. Additionally, in all scenarios the lead-time of deliveries respects the next-day constraint (i.e. all orders taken today are delivered tomorrow). Consequently, in each scenario, the fleet size adapts in order to carry the goods during the available time-window.

Table II presents the main results of the 4 simulated scenarios. The performance indicator "Driven kilometres per Ton of goods" represents how many kilometres are travelled in order to deliver one ton of goods.

TABLE II. RESULTS OVERVIEW FOR THE 4 SIMULATION SCENARIOS

\begin{tabular}{|c|c|c|c|c|}
\hline & $\begin{array}{c}\text { Scenario 0 } \\
\text { Trucks } \\
\mathbf{8 : 0 0 - 1 2 : 0 0}\end{array}$ & $\begin{array}{c}\text { Scenario 1 } \\
\text { Vans } \\
\mathbf{8 : 0 0}-\mathbf{1 2 : 0 0}\end{array}$ & $\begin{array}{c}\text { Scenario 2 } \\
\text { Trucks } \\
\mathbf{9 : 0 0}-\mathbf{1 1 : 3 0}\end{array}$ & $\begin{array}{c}\text { Scenario 3 } \\
\text { Vans } \\
\mathbf{9 : 0 0 - 1 1 : 3 0}\end{array}$ \\
\hline $\begin{array}{c}\text { Driven } \\
\text { kilometres per } \\
\text { Ton of goods }\end{array}$ & 8,16 & 27,70 & 12,45 & 27,96 \\
\hline $\begin{array}{c}\text { Grams of NO } \\
\text { per Ton of } \\
\text { goods }\end{array}$ & 25,29 & 15,24 & 38,60 & 15,38 \\
\hline $\begin{array}{c}\text { Kilograms of } \\
\mathrm{CO}_{2} \text { per Ton } \\
\text { of goods }\end{array}$ & 7,69 & 8,30 & 11,74 & 8,37 \\
\hline $\begin{array}{c}\text { Milligrams of } \\
\mathrm{SO}_{2} \text { per Ton } \\
\text { of goods }\end{array}$ & 58,74 & 63,71 & 89,64 & 64,30 \\
\hline $\begin{array}{c}\text { Loading } \\
\text { rate }\end{array}$ & $56 \%$ & $95 \%$ & $33 \%$ & $94 \%$ \\
\hline $\begin{array}{c}\text { Number of } \\
\text { vehicles }\end{array}$ & 9 & 35 & 16 & 36 \\
\hline
\end{tabular}

Scenario 0 corresponds to the best configuration in terms of "Driven kilometres per Ton of goods", "Kilograms of $\mathrm{CO}_{2}$ per Ton of goods" and "Milligrams of $\mathrm{SO}_{2}$ per Ton of goods". Scenario 1 and 2 return the best results in terms of "Grams of $\mathrm{NO}_{\mathrm{x}}$ per Ton of goods" and represent the second-best solutions in terms of the other emissions.

The time window regulation has a significant impact on the loading rate of the trucks (from $56 \%$ to $33 \%$ ) and consequently on the number of vehicles needed to complete the deliveries (from 9 to 16 trucks). Scenarios 0 and 2 show that if the time for delivery is reduced, the distributor will send partiallyloaded trucks so the delivery tours can end at the requested time. This impact is less significant on Vans (from 95\% to $94 \%$ ), as they have over 6 times less payload capacity than trucks, they are easier to fill even with fewer clients.

As shown in table II, there is significant difference in terms of driven distance between the scenarios $\mathrm{S} 0-\mathrm{S} 2$ and $\mathrm{S} 1-\mathrm{S} 3$, in other words, between trucks and vans. However, this difference is less substantial in the measures related to emissions. Although trucks are capable of carrying more goods, they generate more emissions (see table I) and there tends to be a compensation effect.

Figure 5 presents the results of "Total driven kilometres" (top) and "Driven kilometres per Ton of goods" (bottom) for the four scenarios for a week of simulation time (i.e. 168 hours).

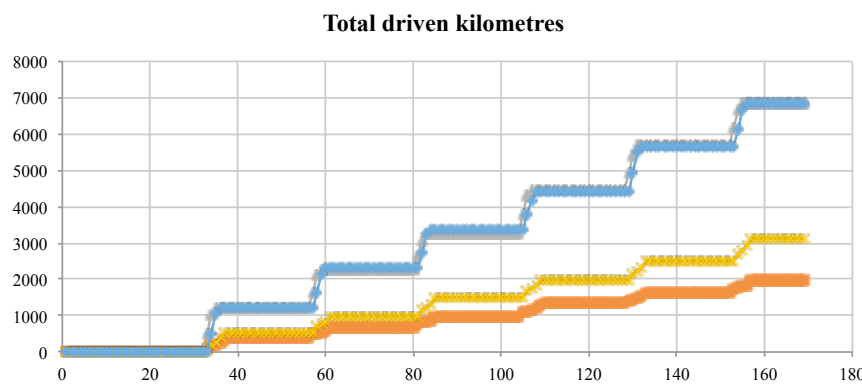

Driven kilometres / Ton of goods delivered

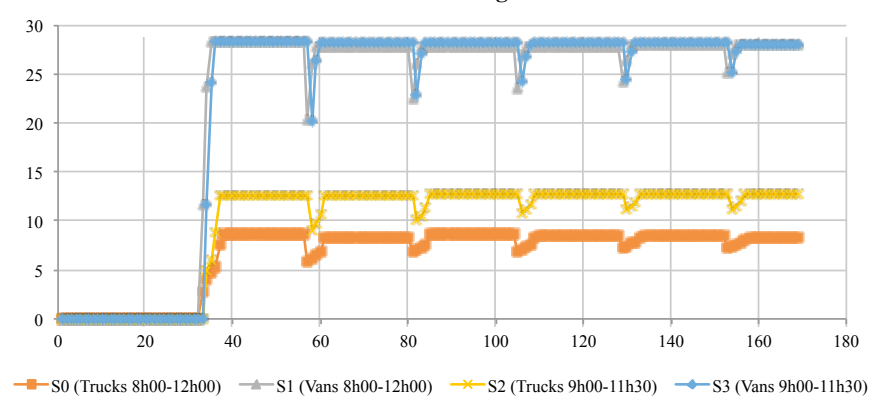

Fig. 5. Evolution of the distance indicators during the simulated week

Since the model considers a next-day delivery rule $(\mathrm{AxB})$, the first day of the simulation is devoted to orders registration. This explains the evolution of the distance indicators in Figure 5 ; in which deliveries begin at $\mathrm{h}=33$ (i.e. 9:00 am of the $2^{\text {nd }}$ day).

Figure 6 presents the results in terms of "Driven kilometres per ton of goods", "Loading rate" and "Number of vehicles" for the four scenarios. 

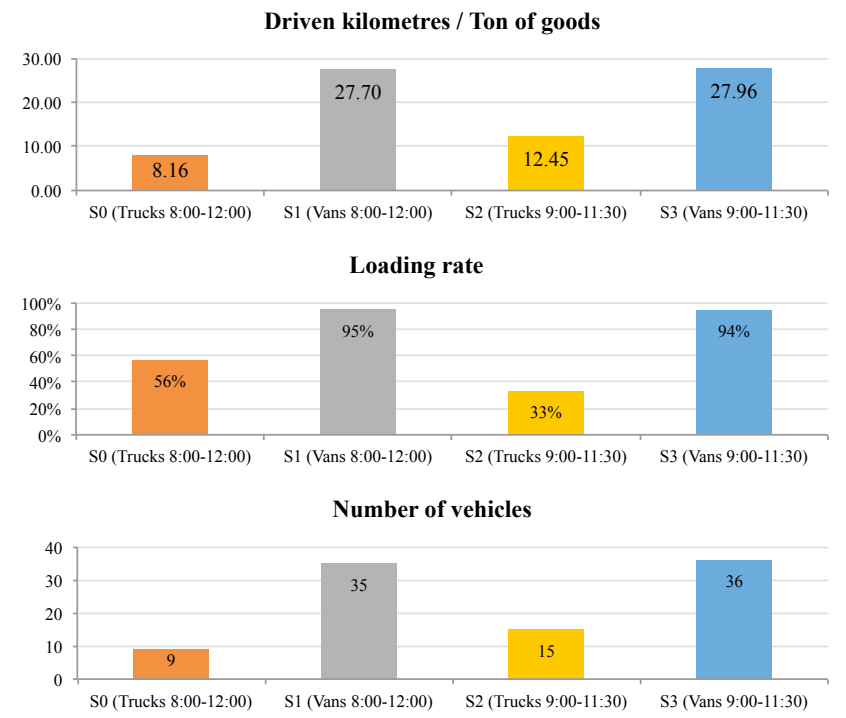

Fig. 6. Results of distance, number of vehicles and loading rates for the 4 scenarios

Figure 7 presents the "Kilograms of $\mathrm{CO}_{2}$ per ton of goods", "Grams of NOx per ton of goods" and "Milligrams of $\mathrm{SO}_{2}$ per ton of goods" for the four scenarios.
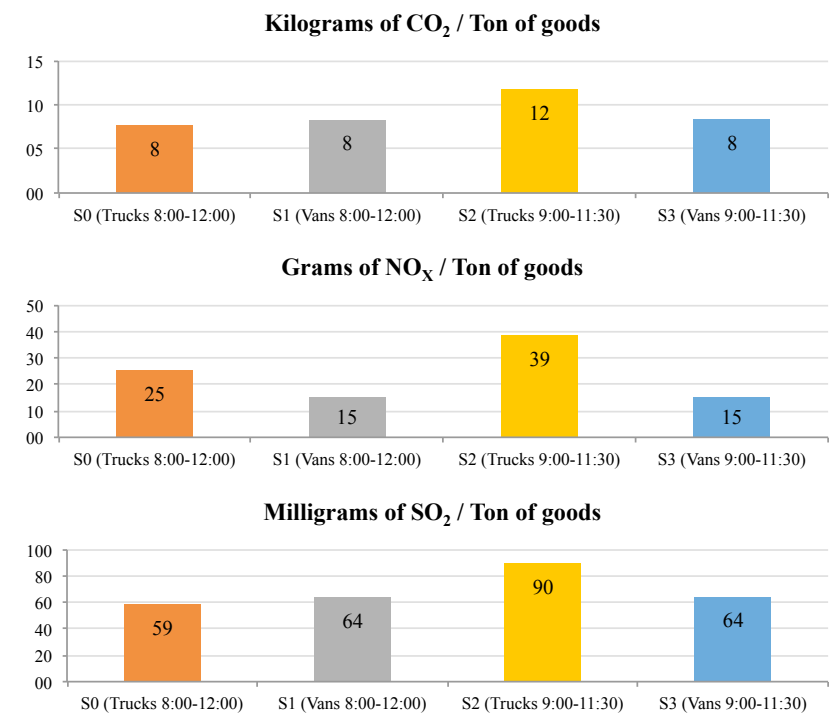

Fig. 7. Results of emissions for the 4 scenarios

The proposed model returns very interesting results; however, these are subject to significant assumptions and should be read with attention. One of the limits of the model corresponds to the indicators that were used to estimate the emissions of the two types of vehicles. Despite basing this data on a rigorous study [18], motorisation technologies and environmental standards evolve rapidly and these results may no longer be representative in a short time. It is important to note that the emission factors considered can add a certain bias to the results. Another limit could be the simplification that the model makes of traffic. A matter of fact, this is modelled by assuming an average speed for vehicles in the urban area, but it is clear that such speed should vary according to the hour of the day.

\section{CONCLUSION AND PERSPECTIVES}

The results show that in order to deliver a given amount of goods (and while respecting a certain rule of lead time), highcapacity vehicles generate a lower total distance than low capacity vehicles (in both cases all the goods are delivered and all time constraints are respected). Undeniably, to deliver the same amount of goods, fewer high-capacity vehicles are needed.

It has been found that in the catering sector, delivery tours are strongly limited by the allowed time windows. This means that vehicles could carry more goods, but they would not be able to deliver such products in the slots demanded by the customers (generally restaurants request to be delivered in the morning). Actually, if the same simulations were carried out with later deliveries authorized, for example until 6:00 pm, the load rates of the trucks would reach the same levels as those of the vans.

It is important to note that although trucks have a lower filling rate than vans $(56 \%$ versus $95 \%$ in our scenarios $\mathrm{S} 0$ and $\mathrm{S} 1)$, they generate less $\mathrm{CO}_{2}$ and $\mathrm{SO}_{2}$ emissions $(8.16 \mathrm{~km} /$ ton compared to $12.39 \mathrm{~km} /$ ton, that is over 3 times less). This is a result of several factors. An important one is the density of clients; which if increased, can reduce the commuting between drop-off points and furthermore allow higher loading rates for the same time window. The current model instantiates 100 restaurants in Paris, that correspond to a very small market share of the 13900 restaurants in the city [21]. In fact, distributors could have greater market shares, implying higher customer densities. Therefore, as the density increases, the performance in terms of total distance and emissions is expected to improve.

The pertinence of "replacing heavy goods vehicles by light duty vehicles in order to reduce emissions" is a paradoxical subject. Undeniably, smaller vehicles generate fewer emissions, but because of their lower capacity, more vehicles are needed and more kilometres are driven in order to deliver the same amount of goods. The simulation considers the scenarios S0 (trucks) and S1 (vans) in order to estimate the impacts of a truck ban. The vans travel over three times more kilometres than the trucks to deliver the same quantity of goods at the same level of service. Although the vans are traveling more kilometres, they produce equivalent emissions. Nonetheless, there is a significant increase in the number of vehicles needed to perform the deliveries (9 against 35 ), which has a direct influence in traffic. It can be concluded that in this example, replacing trucks by vans does not necessarily reduces emissions but it does increase the vehicles in the city.

The notion of changing the delivery time-windows in order to reduce the number of vehicles in an urban zone has proven to be erroneous for the example considered here. The simulation shows that time restriction will have a stronger effect on heavyduty vehicles. When comparing scenarios 1 and 3 , it is revealed that these regulations do not significantly influence the performance of light-duty vehicles. However scenarios 0 and 2 show that time-windows have a substantial impact on heavy- 
duty vehicles as the number of trucks almost doubles while the performance on emissions is decreased.

Based on the hypothesis that all the vehicles are fully loaded, in the case of regulations on weight and/or time window, more vehicles will be needed to perform at the same level of service. The new vehicles will entail extra costs that will eventually be paid by the final customers. Moreover, work carried out in [22] shows that an extra cost is already being paid by the citizens in terms of negative externalities (e.g. diseases caused by pollution have social and financial costs). As a perspective, the simulation model should take into account social and economy-related metrics (particularly costs, manpower and other externalities).

In conclusion, the simulations carried-out in this study reveal that implementing regulations of vehicle sizes and timewindows increases the number of vehicles entering urban areas and does not necessarily reduce emissions. Nonetheless, the vehicle sizes, average speeds, and other factors should be considered in order to evaluate the effects on traffic. This is still to be investigated much further with appropriate tools. In the future, the simulation model has to be calibrated with real data (specially in terms of demand) from the catering industry in order to grow closer to reality.

\section{ACKNOWLEDGMENTS}

This work is supported by ADEME (Agency for the Environment and Energy Management), La Poste Group, Mairie de Paris (Paris City Hall), Pomona Group and RENAULT through the Urban Logistics Chair at MINES ParisTech and by the IDB bank.

\section{REFERENCES}

[1] B. O. Herzog, Urban Freight in Developing Cities: SUTP Sourcebook Module 1g, GTZ. Germany, 2010.

[2] L. Dablanc, "Freight transport for development toolkit: Urban freight," Transp. Res. Support World Bank, p. 50, 2009.

[3] J. T. Castro and H. Kuse, "Impacts of large truck restrictions in freight carrier operations in metro manila," J. East. Asia Soc. Transp. Stud., vol. 6, pp. 2947-2962, 2005.

[4] World Bank, "Strategic Urban Transport Policy Directions for Bangkok," World Bank, no. June, 2007.

[5] G. Smith, T. Michell, and B. Shin, "Assessing the effects of Trucking Regulation in Korea," World Bank Transp. Dep., vol. 47, no. 1, p. 73, 1987.
[6] E. G. Jim LaBelle, Sheena Frève, "Off-Peak Delivery A Pilot Project for the Chicago Region," Chicago, 2015.

[7] National Economic and Development Authority (NEDA), "The truck ban in Metro Manila's major thoroughfares: A policy analysis, Metro Manila.," 1981.

[8] H. J. Quak and M. B. M. de Koster, "Delivering Goods in Urban Areas: How to Deal with Urban Policy Restrictions and the Environment," J. Transp. Sci., vol. 43, no. 2, pp. 211-227, 2009.

[9] S. Jlassi, S. Tamayo, and A. Gaudron, "Simulation applied to urban logistics: a state of the art," in International Conference on City Logistics., 2017.

[10] M. F. H. Bhuiyan, "Traffic Management in Urban Areas under Freight Regulatory Initiatives," Concordia University Montreal, Quebec, Canada, 2011.

[11] P. O. Siebers, C. M. Macal, J. Garnett, D. Buxton, and M. Pidd, "Discrete-event simulation is dead, long live agent-based simulation!," J. Simul., vol. 4, no. 3, pp. 204-210, 2010.

[12] A. Motraghi and M. V. Marinov, "Analysis of urban freight by rail using event based simulation," Simul. Model. Pract. Theory, vol. 25, pp. 7389, 2012.

[13] S. Schroeder, M. Zilske, G. Liedtke, and K. Nagel, "Towards a MultiAgent Logistics and Commercial Transport Model: The Transport Service Provider's View," Procedia - Soc. Behav. Sci., vol. 39, pp. 649663, 2012.

[14] D. Tamagawa, E. Taniguchi, and T. Yamada, "Evaluating city logistics measures using a multi-agent model," Procedia - Soc. Behav. Sci., vol. 2, no. 3, pp. 6002-6012, 2010

[15] J. W. Joubert, P. J. Fourie, and K. W. Axhausen, "Large-Scale AgentBased Combined Traffic Simulation of Private Cars and Commercial Vehicles," Transp. Res. Rec. J. Transp. Res. Board, vol. 2168, no. 1, pp. 24-32, 2010 .

[16] E. Fatnassi and J. Chaouachi, "Discrete Event Simulation of Loading Unloading Operations in a Specific Intermodal Transportation Context," in Software Engineering Perspectives and Application in Intelligent Systems, 2016, pp. 435-444.

[17] W. Van Heeswijk, M. Mes, and M. Schutten, "An agent-based simulation framework to evaluate urban logistics scheme An agentbased simulation framework to evaluate urban logistics schemes," vol. 501, no. March, 2016

[18] E. den Boer, M. Otten, and H. van Essen, "Comparison of various transport modes on a EU scale with the STREAM database," Delft, 2011.

[19] J. Allen, M. Browne, T. Cherrett, and F. McLeod, "Review of UK Urban Freight Studies," Green Logist., no. November, 2008.

[20] CERTU, "Aménagement des aires de livraison - Guide pour leur quantification, leur localisation et leur dimensionnement," 2009.

[21] APUR, "L'évolution des commerces à Paris: Inventaire des commerces 2014 et évolutions 2011-2014," 2015.

[22] F. Carrabs, R. Cerulli, and A. Sciomachen, "An exact approach for the grocery delivery problem in urban areas," Soft Comput., 2016. 